\title{
CASSIOPE Enhanced Polar Outflow Probe (e-POP) Mission Overview
}

\author{
A.W. Yau' ${ }^{1}$ H.G. James ${ }^{1}$
}

Received: 21 October 2014 / Accepted: 22 January 2015 / Published online: 7 March 2015

(C) The Author(s) 2015. This article is published with open access at Springerlink.com

\begin{abstract}
The Enhanced Polar Outflow Probe (e-POP) on the polar-orbiting CASSIOPE small satellite $\left(325 \times 1500 \mathrm{~km}, 80^{\circ}\right.$ inclination $)$ is a suite of 8 plasma instruments, including imaging plasma and neutral particle sensors, magnetometers, dual-frequency Global Positioning System (GPS) receivers, charge coupled-device (CCD) cameras, a radio wave receiver and a beacon transmitter. The scientific objective of e-POP is to make observations of mesoscale and microscale plasma processes in the topside high-latitude ionosphere at the highest-possible resolution, specifically to study the microscale characteristics of plasma outflow and related acceleration processes, the occurrence morphology of neutral escape, and the effects of auroral currents on plasma outflow and those of plasma microstructures on radio propagation: the strategy is to use the large data storage and high-speed telemetry downlink capacity of a companion, experimental communications payload on board CASSIOPE to support the high-resolution observations of particle distributions, waves and magnetic fields to 10 -ms time scale ( $~ 100 \mathrm{~m}$ spatial scale) and the imaging of the aurora on 100 -ms time scale, as well as imaging studies of the ionosphere in conjunction with groundbased transmitters and ground receiving stations on comparable (10-100 ms) time scales.
\end{abstract}

Keywords Ion outflow · Wave particle interaction · Aurora - Satellite observation · Ionosphere $\cdot$ Radio propagation

\section{Introduction}

The high-latitude (auroral and polar) ionosphere is the crossroads of the magnetosphereionosphere-thermosphere (MIT) system. It is directly coupled to the magnetosphere in mass and energy via ion outflows, auroral particle precipitation, and mapping of magnetospheric electric fields, and to the upper atmosphere and thermosphere in mass and momentum via charge exchange, photo-ionization, and Joule heating (Yau and Andre 1997).

\footnotetext{
$凶$ A.W. Yau

yau@ucalgary.ca

1 Department of Physics and Astronomy, University of Calgary, Calgary, AB T2N1N4, Canada
} 
In the context of MIT coupling, the topside ionosphere is a critical transition altitude region between the collision-dominated region below and the collision-less and transportdominated region above. It is closely coupled with the thermosphere via Joule heating, dissociative ion recombination, and charge exchange reactions, in which the underlying ionneutral collisions produce fast or hot neutral hydrogen or oxygen atoms, leading to changes in neutral composition and temperature, the formation of neutral polar wind (Gardner and Schunk 2009) and oxygen geo-corona (Richards et al. 1994).

Wave particle interaction processes are an important part of the MIT coupling equation. Fluid processes around the $\mathrm{F}$ region peak such as the gradient-drift instability give rise to large-scale density irregularities, while microscale plasma instabilities result in localized plasma acceleration and related energy and mass transport processes as well as smallerscale irregularities. It is possible to infer the shapes of these irregularities by measuring the amplitude, polarization, Doppler shift and signal delay time of a high-frequency wave transmitted from a ground transmitter to an orbiting spacecraft (or vice versa) in a 2-point radio propagation experiment, as the ionosphere can refract, scatter, amplify, damp or through non-linearity decompose an electromagnetic wave traversing through it.

The Enhanced Polar Outflow Probe (e-POP) was conceived as part of the multi-purpose CASSIOPE small satellite mission, and a low-cost plasma physics "mission of opportunity" for the investigation of ion outflow and related neutral, auroral and radio processes in the topside ionosphere at high resolution, by utilizing the special data communications capabilities of the companion, experimental Cascade communications payload on CASSIOPE.

Ion outflows from the high-latitude ionosphere are believed to influence the cross-polarcap potential and the onset of magnetic reconnection on both the dayside and the night side (Winglee et al. 2002; Brambles et al. 2013). The different ion outflow populations are highly variable in composition, energy, space and time, and fall into two categories in general: bulk ion flows, including the polar wind and auroral bulk ion up-flow; and suprathermal ion outflows, including ion beams, ion conics, transversely accelerated ions and upwelling ions. See for example the recent review of Yau et al. (2011).

Abe et al. (1993, 2004) observed significant fluxes of "heavy" oxygen ions on Akebono, "mixed" in with thermal-energy "light" $\mathrm{H}^{+}$ion polar wind above their expected maximum altitude in the presence of the Earth's gravity. Engwall et al. (2009) discovered cold hydrogen ions in the distant magnetosphere that were previously "hidden" due to positive spacecraft charging on the Cluster satellites. These and other recent satellite observations (e.g. Peterson et al. 2001) point to the importance of polar wind and auroral bulk upflow as a source of cold plasma for energetic ions at higher altitudes, and underscore the scarcity of low-energy ion observations in the topside ionosphere where the majority of the outflows originate, compared with observations at higher energies and altitudes on Freja (Andre et al. 1998) and FAST (Strangeway et al. 2005).

In the topside high-latitude ionosphere the underlying acceleration processes of lowenergy ion outflows are believed to be an integral part of the auroral system, and intimately connected to the electric field, field-aligned current, electron precipitation, and lowfrequency plasma waves in the aurora. Strong auroral field-aligned currents can drive plasma instabilities, and the resulting wave-particle interaction can lead to perpendicular ion acceleration (Andre et al. 1998). Precipitating, soft auroral electrons produce enhanced ambipolar electric field, leading to up-flow of ions to acceleration regions at higher altitudes (Strangeway et al. 2005), and they enhance electron-impact ionization, leading to density structures that can scatter radio waves and distort their propagation.

As the polar wind and other low-energy ions flow upward along the geomagnetic field lines in the topside ionosphere, they undergo charge exchange reactions with background 
thermal neutrals and hot geo-coronal atoms. Such reactions involve the transfer of an electron from the neutral to the ion, and as noted above produce a streaming neutral atom, which will escape the Earth's gravitation if the original ion had sufficient energy before the reaction.

The microscale structures of the respective plasma acceleration and wave processes are embedded in characteristic mesoscale topology. Significant horizontal density gradients exist in the cusp, auroral oval, and adjoining regions, in structures such as troughs, polar patches and traveling ionospheric disturbances. It is therefore important to understand the ionospheric dynamics that couple the comparatively large scales to the smaller ones associated with aurora, which are the targets of in-situ observation on e-POP.

\section{Science Objectives and Planned Investigations}

In the context of plasma outflows as a part of the MIT systems, the scientific objectives of e-POP are to investigate micro-scale plasma outflow and related neutral escape processes in the polar ionosphere-thermosphere; and the effects of auroral currents and acceleration processes on plasma outflow, ionospheric density structures, and radio propagation (Yau et al. 2006). The topics of investigations include: (1) topside ionospheric ion upflow and acceleration, (2) thermospheric heating and escape, (3) auroral currents and acceleration, (4) radio wave propagation, and (5) active ionospheric heating.

The e-POP mission comprises three interconnected components: a small-satellite component to investigate atmospheric and plasma flows and related wave-particle interaction processes in the topside ionosphere in-situ, coordinated ground- and other space-based measurements, and a theoretical assimilation component.

\subsection{Topside ionospheric ion upflow and acceleration}

Yau et al. (2011) reviewed the different aspects of thermal and suprathermal ion outflows, including the polar wind (Yau et al. 2007). Both ion outflow categories are strongly influenced by the solar EUV irradiance and solar wind energy input (Cully et al. 2003) and the state of the magnetosphere-ionosphere-thermosphere, and both exhibit significant seasonal variations (Redmon et al. 2012; Yau et al. 1985). Compared with $\mathrm{H}^{+}$and $\mathrm{He}^{+}, \mathrm{O}^{+}$exhibits a much stronger dependence on magnetic and solar activity, the active-to-quiet time and solar maximum-to-minimum ratios of the energetic $\mathrm{O}^{+}$ion outflow rate being $\sim 20$ and $\sim 5$, respectively (Yau et al. 1988).

In the topside ionosphere and above, the polar wind and auroral bulk ion up-flow generally originate from above and below the $\mathrm{H}-\mathrm{O}$ crossover altitude, respectively. Therefore, the polar wind is typically dominated by hydrogen, and the bulk auroral ion upflow dominated by oxygen. In both cases, the observed ion velocity is on average larger and the ion flux lower at solar minimum than at solar maximum (Abe et al. 2004; Ogawa et al. 2010).

Both thermal ion outflow populations constitute an important source of low-energy plasma for suprathermal ion outflows above the topside ionosphere, where transverse ion acceleration results in the subsequent generation of ion conics, and parallel electric field and magnetic folding contribute to the formation of ion beams at higher altitudes. At auroral latitudes, transverse ion acceleration often occurs within localized regions only tens of meters wide, in association with localized lower-hybrid waves or "spikelets" (Kintner et al. 1992) and intense broadband ELF waves in the dayside cleft ionosphere (Kintner et al. 1996). 
Ion composition and related particle and wave observations on e-POP will be used to investigate (a) the influence of the interplanetary magnetic field (IMF) on dayside thermal outflows and polar ion composition distribution, (b) the acceleration of atomic nitrogen and molecular ions at F-region and topside altitudes during substorm or magnetic-storm times, (c) the effects of ion-neutral collisions on thermal polar wind and auroral bulk flow in a solar rotation cycle, and (d) the role of ion convection in plasma intermixing in the polar topside ionosphere.

\subsection{Thermospheric heating and escape}

Both polar wind and auroral bulk up-flow ions undergo charge exchange reactions in the topside ionosphere with the background thermal neutrals and with hot geo-coronal atoms that may be present. The resulting neutral particle will escape the Earth's gravitation if the original ion has sufficient energy before the reaction. In particular, hydrogen and oxygen ions undergo fast resonant charge exchange with their respective parent neutral atoms (i.e. $\mathrm{H}^{+}+\mathrm{H} \leftrightarrow \mathrm{H}+\mathrm{H}^{+} ; \mathrm{O}^{+}+\mathrm{O} \leftrightarrow \mathrm{O}+\mathrm{O}^{+}$) as well as accidentally resonant charge exchange with neutral atoms of the other species (i.e. $\mathrm{H}^{+}+\mathrm{O} \leftrightarrow \mathrm{H}+\mathrm{O}^{+} ; \mathrm{H}+\mathrm{O}^{+} \leftrightarrow \mathrm{H}^{+}+\mathrm{O}$ ), resulting in fast (high-speed) and hot (high-temperature) neutral hydrogen and oxygen atoms.

Likewise, resonant charge exchange is expected to occur between neutral helium and helium ions in the open field-line region of the topside polar ionosphere, helium being a minor component of the polar wind; the resulting atmospheric helium outflow is believed to constitute a significant mechanism for the attrition of terrestrial helium out-gassed from the Earth's crust (Axford 1968).

In the cusp region, the CHAMP satellite regularly observed neutral mass density enhancement (Lühr et al. 2004) in regions of ion up-flows near the cusp or the cleft. The observed enhancement was as large as $200 \%$ at $410 \mathrm{~km}$ altitude during times of large geomagnetic storms, and has been attributed to soft precipitating electrons (Sadler et al. 2012), which result in a sequence of increased ambient electron heating, plasma pressure, ambipolar electric field, ion upwelling (up-flow) and resulting neutral "drag" (up-flow or expansion). The precipitating electrons also lead to large-amplitude, small-scale field-aligned current structures, which result in increased Joule heating and increased ion and neutral temperatures.

The high-resolution particle (ion, neutral and soft electron) and magnetic field observations on e-POP will be used to investigate (a) the quantitative roles of ion up-flow, soft electron precipitating flux, and small- and large-scale field-aligned currents in neutral density enhancement and/or upwelling in the cusp and various auroral regions, (b) the neutral and ion composition distributions in regions of neutral density enhancement, (c) the possible presence of neutral polar wind and its composition below and above the crossover height, and (d) the impact of charge-exchange reactions on ion-outflows and neutral escape at higher altitudes.

\subsection{Auroral Currents and Acceleration}

An important question in ion up-flow and acceleration is the micro-scale relationship between auroral bulk ion up-flow, heating, and acceleration in the topside ionosphere, and the associated auroral emissions, field-aligned currents, and plasma waves. There are a number of latitudinal spatial scales associated with auroral arcs, from the 10-100 km wide band system that often appears as one single broad arc from space, to the $0.1-1 \mathrm{~km}$ thin curtain that can be observed using ground based high-resolution imaging (Borovsky 1993). A large 
variety of highly dynamic small-scale structures exist within the visible aurora, including auroral filaments, curls, and spirals, and features associated with extremely rapid motions ( $>10 \mathrm{~km} / \mathrm{s}$ ) and temporal variations (time constants of 1-60 s) (Trondsen and Cogger 1998) that have apparent widths on the order of 10-100 $\mathrm{m}$ at the magnetic zenith. Such structures suggest the presence of auroral acceleration processes of electron or ion gyroradius scale size. Localized lower-hybrid solitary structures were observed in density depletions of similar size (Knudsen et al. 2004).

High time-resolution auroral images will be used in conjunction with particle and field data on e-POP to investigate (a) the small-scale (sub-km) structures of rapidly varying (subsecond scale) aurora, (b) the corresponding structures in auroral electron precipitation, (c) the relationship between these structures and the auroral current system, and (d) the possible connection between auroral ion up-flow and transverse ion acceleration in the topside ionosphere.

\subsection{Radio Wave Propagation}

Significant horizontal density gradients exist in the cusp, auroral oval, and adjoining regions, in structures such as troughs, polar patches and traveling ionospheric disturbances. Radio imaging of ionospheric density irregularities embedded in these mesoscale structures provide an effective means with which to investigate the physics of trans-ionospheric radio wave propagation and to determine (visualize) the shape and distributions of the density structures (e.g., James et al. 2006) - and a powerful complement to in-situ observation of thermal and suprathermal plasma and concomitant waves inside regions of plasma microinstabilities. A number of different and complementary radio imaging techniques are possible using the respective radio instruments on e-POP in conjunction with other ground-based or space-borne transmitters or receivers.

Using the radio receiver instrument (RRI) in conjunction with various ground transmitters, it is possible to conduct a 2-point radio propagation experiment to measure the amplitude, polarization, Doppler shift and signal delay time of the incoming wave onboard to reconstruct the shapes of irregularities in the ionosphere. In the case of the Saskatoon SuperDARN radar, the state of polarization of the signal at the ground receiver may also be measured using a full polarimeter at the radar, to infer the detailed ionospheric conditions along the propagation path.

In addition, the polarization measurements may be combined with the interferometric measurement by the radar to identify the propagation modes. The scattered signal received by the SuperDARN receiver from the range cell traversed by e-POP may be used to deduce the small-scale $(\sim 100 \mathrm{~m})$ or mesoscale $(\sim 1 \mathrm{~km})$ scattering ionospheric structures (Tsunoda et al. 1989), and to determine the responsible scattering mechanism. Candidate mechanisms include coherent scattering by plasma waves generated by gradient-drift instability, and "partial reflections" from gradients in ionospheric plasma density.

Figure 1 illustrates the relationship between e-POP, the ground facilities, and ionospheric targets in such a 2-point radio propagation experiment. A ground HF radar such as SuperDARN irradiates the $\mathrm{E}$ and $\mathrm{F}$ regions of the high-latitude ionosphere, and receives backscatter from density irregularities in both the $\mathrm{E}$ and $\mathrm{F}$ regions. F-region scatter can be detected on both direct paths such as path " $b$ " and one-hop paths such as path " $a$ ", which involves an oblique reflection and a subsequent ground-reflection before backscatter from ionospheric irregularities located beyond the right side of the diagram. The intensity of scattered or smoothly propagated radar waves is followed as a function of the position of the orbiting receiver, giving information about the angular distribution of the scatter. 
Fig. 1 Coordinated observation of radio propagation using the radio receiver instrument onboard CASSIOPE/e-POP in conjunction with ground $\mathrm{HF}$ radar facilities such as SuperDARN

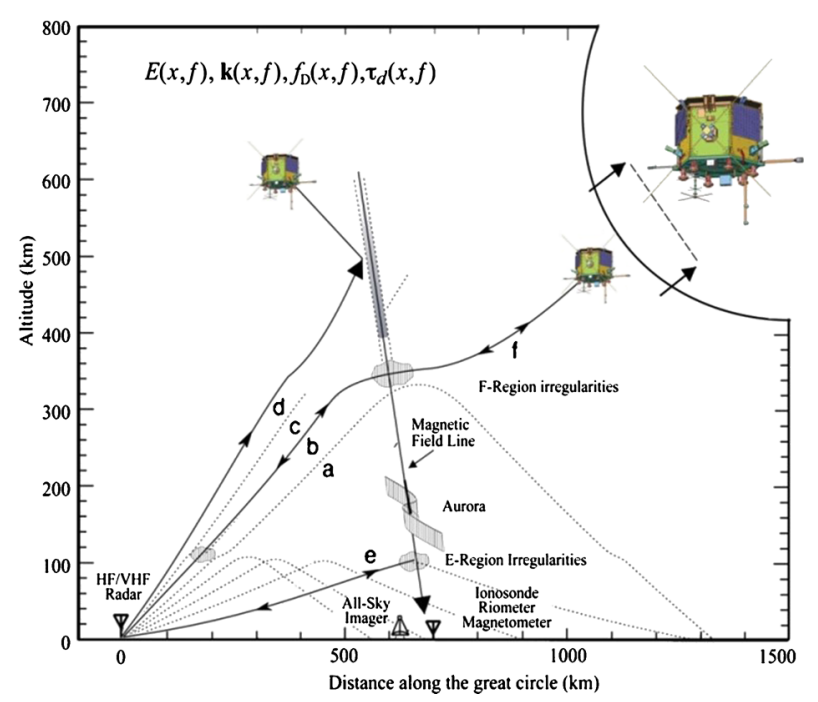

Using the differential Global Position System (GPS) receiver on e-POP, ionospheric tomographic measurements may be performed in conjunction with the constellation of GPS satellites. In the case of a ground-based GPS receiver, the Earth's ionosphere and atmosphere act as a dispersive medium for the L1 and L2-band waves emitted by the GPS satellite; thus the atmospheric and ionospheric density distributions modify the phase and amplitude of the waves and the total electron content (TEC) distribution may be inferred from the gradually changing phase delays. In the case of e-POP, the relative motion of the orbiting satellite with respect to an occulted GPS satellite produces a "tomographic" sweeping of the plasma density distribution with height of the low layers of the ionosphere through which the connecting L-band rays pass, from which the corresponding large-scale ion outflow distribution may be inferred under favorable geometry between the satellites using the technique of Yizengaw et al. (2006).

Similar tomographic measurements are to be made using the beacon transmitter on ePOP. In this technique, coherent electromagnetic waves at two or more frequencies in the VHF-UHF frequency range are transmitted from the coherent electromagnetic radio (CER) beacon on e-POP. Their signals are received at an array of ground receiving stations, and the measured signals at the different stations are combined to determine the distribution of radio scintillation and corresponding irregularities.

\subsection{Ionospheric Heating}

The intentional deposition of radio wave energy in the atmosphere by powerful groundbased transmitters has developed into a tool used extensively for active investigation of the ionosphere-thermosphere-magnetosphere (ITM) system (National Academy of Sciences 2014). Already e-POP measurements have been coordinated with operations of highfrequency heaters, including HAARP (Gakona, Alaska), SPEAR (Longyearbyen, Norway), EISCAT Heating (Troms $\varnothing$, Norway), and Sura (Vasil'sursk, Russia).

Heater-coordinated observations on CASSIOPE focus on a number of important scientific goals. The relevant history begins in the bottom-side F region, where electromagnetic pump waves of great intensity near their total reflection height trigger parametric decay (Fejer 1979) into electrostatic waves whose damping or collapse leads to electron and ion 
heating. Stimulated electromagnetic emissions (SEE) (Leyser 2001) and enhanced optical emissions (Bernhardt et al. 2012) may be produced. Field-aligned striations of density can also appear. Clarification of these basic phenomena will be enhanced by CASSIOPE when it is in or close to the heated volume, by observations of the instruments onboard.

In the auroral ionospheric D and E region, a high-powered heater modulated at an ELF or VLF frequency can cause the modulation of the auroral electrojet current at the same frequency. This results in the launch of ELF/VLF waves; the stimulation of energetic electron flux in the magnetospheric equatorial region and the subsequent ohmic heating of ambient electrons in the ionosphere are other consequences (Rietveld et al. 1984). These would be detected by e-POP. Another tactic for driving VLF currents in the F region that can likewise radiate, without the need for an electrojet current, has been suggested by Papadopoulos et al. (2011).

In addition to the above, man-made EM radiations at other carrier frequencies interact with the ITM in ways that may be observable from CASSIOPE. Electron energization by VLF waves from a high-power VLF transmitter was recently observed on Demeter (Gamble et al. 2008). Investigations of waves and particles in this region may broaden understanding of plasma processes controlling the magnetospheric radiation belts. The short review above is mostly limited to processes occurring near CASSIOPE orbital heights, and has largely excluded possible mechanisms occurring at magnetospheric altitudes (National Academy of Sciences 2014).

\section{Science Payload}

To achieve its science objectives above, e-POP focuses on quantitative in-situ measurements of small-scale plasma, waves, and fields at the highest possible spatial-temporal resolution, and imaging and tomographic measurements of the meso- and large-scale auroral morphology and ionospheric topology. To meet these measurement objectives, the concept of the mission is based on a plasma instrument payload consisting of a complement of in-situ, imaging, and "tomographic" instruments, on an elliptical polar-orbiting small satellite with substantial onboard data storage and telemetry downlink capabilities. To achieve the optimum altitude, local time, and seasonal sampling for the respective measurements, the 3-axis stabilized CASSIOPE spacecraft was launched into an orbit with a perigee of $325 \mathrm{~km}$, an apogee of $1500 \mathrm{~km}$, and an inclination of $81^{\circ}$. Table 1 summarizes the measurement objectives of the eight e-POP science instruments, along with the respective instrument principal investigators. Figure 2 shows the layout of the instruments on the CASSIOPE spacecraft.

The e-POP science payload includes 4 "in-situ" ( 3 particle and 1 magnetic field), 1 optical imaging, and 3 radio instruments. The two plasma imaging sensors measure ion and electron distributions to the time scale of 10-ms (spatial scale of $\sim 70 \mathrm{~m}$ ). The imaging and rapidscanning ion mass spectrometer (IRM) measures the composition (density) of major and minor ions as well as the drift velocity and temperature of major ions in the thermal and suprathermal $(0.5-100 \mathrm{eV})$ energy range and the mass-per-charge range of 1-60 (AMU/e).

The suprathermal electron imager (SEI) measures the electron energy and angular (pitchangle) distributions of suprathermal electrons and ions in the 2-200 eV range, including atmospheric photoelectrons, and soft precipitating electrons.

The neutral mass and velocity spectrometer (NMS) measures the density, velocity and temperature of major neutral atmospheric species, particularly $\mathrm{O}$ and $\mathrm{N}_{2}$, and distinguishes between the ambient and the fast or hot neutral atoms or molecules. 
Table 1 e-POP science instruments

\begin{tabular}{|c|c|c|c|}
\hline & Instrument & Principal Investigator & Measurements \\
\hline IRM & $\begin{array}{l}\text { Imaging rapid mass } \\
\text { spectrometer }\end{array}$ & $\begin{array}{l}\text { A.W. Yau } \\
\text { (University of Calgary) }\end{array}$ & $\begin{array}{l}0.5-100 \mathrm{eV} \text { ions: composition, } \\
\text { energy and 3D angular distributions }\end{array}$ \\
\hline SEI & Suprathermal electron imager & $\begin{array}{l}\text { D.J. Knudsen } \\
\text { (University of Calgary) }\end{array}$ & $\begin{array}{l}\text { 2-200 eV electrons or ions: energy } \\
\text { and } 2 \mathrm{D} \text { angular distributions }\end{array}$ \\
\hline NMS & $\begin{array}{l}\text { Neutral mass and velocity } \\
\text { spectrometer }\end{array}$ & $\begin{array}{l}\text { H. Hayakawa } \\
\text { (JAXA/ISAS) }\end{array}$ & $\begin{array}{l}0.1-2 \mathrm{~km} / \mathrm{s}, 1-40 \text { AMU neutrals: } \\
\text { composition, velocity, temperature }\end{array}$ \\
\hline FAI & Fast auroral imager & $\begin{array}{l}\text { L.L. Cogger } \\
\text { (University of Calgary) }\end{array}$ & $\begin{array}{l}630 \mathrm{~nm} \text {, near infrared (650-1100 } \\
\mathrm{nm}) \text { auroral images }\end{array}$ \\
\hline RRI & Radio receiver instrument & $\begin{array}{l}\text { H.G. James } \\
\text { (University of Calgary) }\end{array}$ & $\begin{array}{l}\text { ELF-HF waves: electric field } \mathbf{E}(\omega) \\
\text { and wave vector } \mathbf{k}(\omega)\end{array}$ \\
\hline MGF & Magnetic field instrument & $\begin{array}{l}\text { D.D. Wallis } \\
\text { (Magnametrics) }\end{array}$ & $\begin{array}{l}\text { Magnetic field perturbation } \Delta \mathbf{B} \text {, } \\
\text { field-aligned current } \mathrm{j} / /\end{array}$ \\
\hline GAP & $\begin{array}{l}\text { GPS-based position, attitude } \\
\text { and profiling }\end{array}$ & $\begin{array}{l}\text { R.B. Langley } \\
\text { (Univ. of New Brunswick) }\end{array}$ & $\begin{array}{l}\text { Spacecraft position and attitude; total } \\
\text { electron content (TEC) }\end{array}$ \\
\hline CER & $\begin{array}{l}\text { Coherent EM radio } \\
\text { tomography }\end{array}$ & $\begin{array}{l}\text { P.A. Bernhardt } \\
\text { (Naval Research Lab) }\end{array}$ & TEC and scintillation \\
\hline
\end{tabular}

JAXA = Japan Aerospace Exploration Agency; ISAS = Institute of Space and Astronautical Science

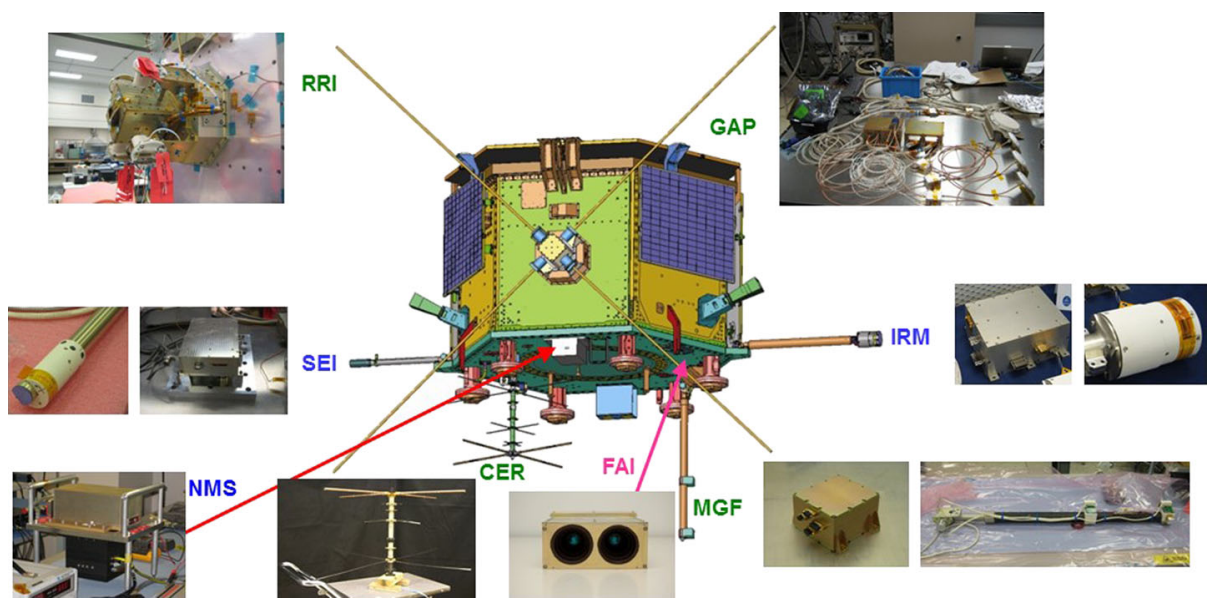

Fig. 2 e-POP instrument payload layout on CASSIOPE

The magnetic field instrument (MGF) consists of two spaced fluxgate magnetometers, and measures the vector magnetic field at 160 samples s$^{-1}$; from the measured field, fieldaligned current structures may be inferred at $\sim 90$-m spatial resolution.

The fast auroral imager (FAI) consists of two cameras, and images the distributions of auroral emission intensity at $630 \mathrm{~nm}$ and in the near-infrared (NIR; 650-1100 nm), respectively, with an exposure time of 100-ms (nominal frame rate of 1 or 2 frames per second) in the NIR and a maximum pixel resolution of $400 \mathrm{~m}$ near perigee.

The radio receiver instrument (RRI) consists of two pairs of 3-m monopoles, and measures radio waves from both natural and artificial sources, from extremely low frequency (ELF) to high frequency (HF) at a maximum sampling rate of $62500 \mathrm{~s}^{-1}$. It measures the 
electric field amplitude and polarization of the detected waves, as well as the direction of arrival, Doppler shift and signal delay in the case of electromagnetic radio waves from ground transmitters.

The GPS-receiver based position, attitude and profiling instrument (GAP) consists of an array of 5 dual-frequency GPS receivers connected to a network of 4 patch antennas and an occultation antenna, and it measures the pseudo-range and carrier phase of the incoming GPS signals in the L1 and L2 bands, from which the spacecraft position, velocity and attitude and total electron contents may be derived at up to 100 samples per second.

The coherent electromagnetic radio tomography experiment (CER) consists of a trifrequency beacon transmitter, and can will transmit at up to $3 \mathrm{VHF}-\mathrm{UHF}$ frequencies to perform total-electron-content and scintillation measurements in conjunction with ground receiving stations.

\section{Mission Operations and Data Analysis}

The science operation phase of CASSIOPE began in late November 2013, after the completion of the two-month commissioning phase. Several science investigations are being undertaken in this phase, including the study of sub-decameter ionospheric structures in the topside ionosphere, small-scale aurora structures using auroral tomography, 3-dimensional polar wind velocity distributions, neutral upwelling, plasmasphere mass loading, ion outflow tomography, coordinated radio propagation experiments, and coordinated active heating experiments, to name a few. A number of these investigations aim to take advantage of the unique measurement resolution capabilities of the e-POP instruments, the onboard data storage capacity and telemetry bandwidth of the Cascade payload, and the versatile attitude pointing capability of the CASSIOPE spacecraft.

In each investigation, the spacecraft is placed in a specific attitude. In "nadir-pointing" attitude, the FAI cameras view in the nadir direction. In "ram-pointing", the spacecraft ram direction is along the RRI antennas' bore sight and lies in the entrance aperture planes of NMS, IRM and SEI, to facilitate neutral and low-energy charged particle measurements in the ram direction. In "inertial-pointing", the spacecraft maintains its orientation so that a specific instrument views a certain inertial direction continuously, e.g., FAI views the limb to obtain aurora or airglow emission altitude profiles in limb-pointing attitude. In "slewpointing", the spacecraft slews its attitude slowly while traversing a specific target on the ground or in space, so that one or more of the instruments point continuously at the target, e.g. the FAI cameras points at a localized region of the auroral zone to image the auroral emission in this region continuously, or the RRI antenna plane remains normal to the direction to a ground transmitter.

To support the respective investigations, science measurements are made primarily during polar orbit passes and less frequently over specific ground locations at lower latitudes, at various altitudes between the perigee and apogee, as the instrument complement operate in a number of science operation modes targeted at specific scientific investigations. In each investigation, selected instruments operate in specific instrument modes and acquire measurement data at maximum data rate and resolution while others acquire data at a reduced rate, depending on the scientific objective of the investigation. A central data handling unit is used to coordinate the collection and onboard processing of data from the respective instruments during an orbit. Thereafter, the data is transferred to the companion Cascade communications payload for subsequent downlink. Cascade is an experimental communications 
payload and uses the downlink of e-POP science data in Ka band to demonstrate the technology of rapid transfer of large data volumes between any two locations on Earth. Typically, up to 15 gigabytes of data can be produced per day for downlink to ground; unfortunately, the operation of the Cascade payload has proved problematic shortly after its successful commissioning and a brief period of nominal operation thereafter, due to technical issues at the subsystem level. Effort is continuing to overcome the underlying intermittent problems of the Cascade payload in order to improve its performance reliability. Reduced science data from an orbit pass is uploaded to the Canadian Space Science Data Portal (cssdp.ca) once it is validated, and made available online through the world-wide web.

\section{Summary}

In summary, the Enhanced Polar Outflow Probe (e-POP) is a part of the multi-purpose CASSIOPE small satellite mission, and a low-cost plasma physics mission for the high-resolution investigation of ion outflow and related neutral, auroral and radio processes in the topside ionosphere.

The mission comprises three interconnected components: a small-satellite component to investigate atmospheric and plasma flows and related wave-particle interaction processes in the topside ionosphere in-situ, and coordinated ground- and other space-based observations, and a theoretical assimilation component.

The primary scientific objectives of e-POP are to investigate micro-scale plasma outflow and related neutral escape processes in the polar ionosphere-thermosphere; and the effects of auroral currents and acceleration processes on plasma outflow, ionospheric density structures, and radio propagation. The topics of investigations include: (1) topside ionospheric ion upflow and acceleration, (2) thermospheric heating and escape, (3) auroral currents and acceleration, (4) radio wave propagation, and (5) active ionospheric heating.

The e-POP science payload is a suite of 8 scientific instruments, including imaging plasma and neutral particle sensors, magnetometers, dual-frequency GPS receivers, CCD cameras, a radio wave receiver and a beacon transmitter. Some of these instruments have unique measurement resolution capabilities and high sampling rates, e.g. IRM, SEI, MGF and RRI, which can sample at $\geq 100$ samples per second.

The complement of instruments operate in a number of science operation modes targeted at specific scientific investigations. Central to the respective investigations is the question of how the topside ionosphere processes the large-scale magnetospheric energy inputs and how the resulting nonlinear wave-particle interaction may produce the small-scale structures and particle acceleration processes. In each investigation, selected instruments operate in specific instrument modes and acquire measurement data at maximum data rate and resolution while others acquire data at a reduced rate, depending on the scientific objective of the investigation. Science measurements are made primarily during polar orbit passes and less frequently over specific ground locations at lower latitudes, at various altitudes between the perigee and apogee. Reduced science data from an orbit pass is uploaded to the Canadian Space Science Data Portal (cssdp.ca) once it is validated, and made available online through the world-wide web.

Acknowledgements We gratefully acknowledge the funding support for the e-POP project from the Canadian Space Agency (CSA) and the Natural Science and Engineering Research Council of Canada (NSERC). We also want to thank all e-POP Science Team members, for their instrument and other scientific contributions. 
Open Access This article is distributed under the terms of the Creative Commons Attribution License which permits any use, distribution, and reproduction in any medium, provided the original author(s) and the source are credited.

\section{References}

T. Abe, B.A. Whalen, A.W. Yau, R.E. Horita, S. Watanabe, E. Sagawa, EXOS-D (Akebono) SMS observations of the polar wind. J. Geophys. Res. 98, 11191-11203 (1993)

T. Abe, A.W. Yau, S. Watanabe, M. Yamada, E. Sagawa, Long-term variation of the polar wind velocity and its implication for the ion acceleration process: Akebono suprathermal ion mass spectrometer observations. J. Geophys. Res. 109, A09305 (2004). doi:10.1029/2003JA010223

M. Andre, P. Norqvist, L. Andersen, L. Eliasson, A.I. Eriksson, L. Blomberg, R.E. Erlandson, J. Waldemark, Ion energization mechanisms at 1700 kilometer in the auroral region. J. Geophys. Res. 103, 4199-4222 (1998)

W.I. Axford, The polar wind and the terrestrial helium budget. J. Geophys. Res. 73, 6855-6859 (1968)

P.A. Bernhardt, M. Wong, J.D. Huba, B.G. Fejer, L.S. Wagner, J.A. Goldstein, C.A. Selcher, V.L. Frolov, E.N. Sergeev, Optical remote sensing of the thermosphere with HF pumped artificial airglow. J. Geophys. Res. 105, 10657-10671 (2012)

J.E. Borovsky, Auroral arc thicknesses as predicted by various theories. J. Geophys. Res. 98, 6101-6138 (1993)

O.J. Brambles, W. Lotko, B. Zhang, J. Ouellette, J. Lyon, M. Wiltberger, The effects of ionospheric outflow on ICME and SIR driven sawtooth events. J. Geophys. Res. 118, 6024-6041 (2013). doi:10.1002/ jgra. 50522

C.R. Chappell, T.E. Moore, J.H. Waite Jr., The ionosphere as a fully adequate source of plasma for the Earth's magnetosphere. J. Geophys. Res. 92, 5896-5910 (1987)

C.M. Cully, E.F. Donovan, A.W. Yau, G.G. Arkos, Akebono suprathermal mass spectrometer observations of low-energy ion outflow: dependence on magnetic activity and solar wind conditions. J. Geophys. Res. 108(A2), 1093 (2003). doi:10.1029/2001JA009200

E. Engwall, A.I. Eriksson, C.M. Cully, M. Andre, R. Torbert, H. Vaith, Earth's ionospheric outflow dominated by hidden cold plasma. Nat. Geosci. (2009). doi:10.1038/NGEO387

J.A. Fejer, Ionospheric modification and parametric instabilities. Rev. Geophys. Space Phys. 17, 135-153 (1979)

R.J. Gamble, C.J. Rodger, M.A. Clilverd et al., Radiation belt electron precipitation by man-made VLF transmissions. J. Geophys. Res. 113, A10211 (2008). doi:10.1029/2008JA013369

L.C. Gardner, R.W. Schunk, Supersonic neutral winds and neutral streams in the thermosphere-ionosphereplasmasphere system. Radio Sci. 44, RS0A06 (2009). doi:10.1029/2008RS004053

H.G. James, R.G. Gillies, G.C. Hussey, P. Prikryl, HF fades caused by multiple wave fronts detected by a dipole in the ionosphere. Radio Sci. 41, RS4018 (2006). doi:10.1029/2005RS003385

P.M. Kintner, J. Vago, S. Chesney, R.L. Arnoldy, K.A. Lynch, C.J. Pollock, T.E. Moore, Localized lower hybrid acceleration of ionospheric plasma. Phys. Rev. Lett. 68, 2448 (1992)

P.M. Kintner, J. Bonnell, R. Arnoldy, K. Lynch, C. Pollock, T. Moore, SCIFER-Ion acceleration and plasma waves. Geophys. Res. Lett. 23, 1873-1876 (1996)

D.J. Knudsen, B.J.J. Bock, S.R. Bounds et al., Lower-hybrid cavity density depletions as a result of transverse ion acceleration localized on the gyroradius scale. J. Geophys. Res. 109, A04212 (2004). doi:10.1029/2003JA010089

T.B. Leyser, Stimulated electromagnetic emissions by high-frequency electromagnetic pumping of the ionospheric plasma. Space Sci. Rev. 98, 223-328 (2001)

H. Lühr, M. Rother, W. Köhler, P. Ritter, L. Grunwaldt, Thermospheric up-welling in the cusp region: evidence from CHAMP observations. Geophys. Res. Lett. 31, 805-808 (2004)

National Academy of Sciences, Opportunities for High-Power, High-Frequency Transmitters to Advance Ionospheric/Thermospheric Research. Report of a Workshop, National Academies Press, Washington, DC (2014)

Y. Ogawa, S.C. Buchert, A. Sakurai, S. Nozawa, R. Fujii, Solar cycle dependence of ion upflow in the polar ionosphere observed with the EISCAT Tromso UHF radar. J. Geophys. Res. 115, A07310 (2010). doi:10.1029/2009JA014766

K. Papadopoulos, N.A. Gumerov, X. Shao, I. Doxas, C.L. Chang, HF-driven currents in the polar ionosphere. Geophys. Res. Lett. 38, L12103 (2011)

W.K. Peterson, H.L. Collin, A.W. Yau, O.W. Lennartsson, Polar/toroidal imaging mass-angle spectrograph observations of suprathermal ion outflow during solar minimum conditions. J. Geophys. Res. 106, 6059_ 6066 (2001) 
R.J. Redmon, W.K. Peterson, L. Andersson, W.F. Denig, A global comparison of O+ upward flows at $850 \mathrm{~km}$ and outflow rates at $6000 \mathrm{~km}$ during nonstorm times. J. Geophys. Res. 117, A04213 (2012). doi:10.1029/2011JA017390

P.G. Richards, M.P. Hickey, D.G. Torr, New sources for the hot oxygen geocorona. Geophys. Res. Lett. 21, 657-660 (1994)

M.T. Rietveld, R. Barr, H. Kopka, E. Nielsen, P. Stubbe, R.L. Dowden, Ionospheric beam scanning: a new technique for ELF studies of the auroral ionosphere. Radio Sci. 19(4), 1069-1077 (1984). doi:10.1029/RS019i004p1069

F.B. Sadler, M. Lessard, E. Lund, A. Otto, H. Lühr, Auroral precipitation/ion upwelling as a driver of neutral density enhancement in the cusp. J. Atmos. Sol.-Terr. Phys. 87-88, 82-90 (2012). doi:10.1016/ j.jastp.2012.03.003

R.J. Strangeway, R.E. Ergun, Y.J. Su, C.W. Carlson, R.C. Elphic, Factors controlling ionospheric outflows as observed at intermediate altitudes. J. Geophys. Res. 110, A03221 (2005). doi:10.1029/2004JA010829

T.S. Trondsen, L.L. Cogger, A survey of small-scale spatially periodic distortions of auroral forms. J. Geophys. Res. 103, 9405-9415 (1998). doi:10.1029/98JA00619

R.T. Tsunoda, R.C. Livingston, J.F. Vickrey et al., Dayside observations of thermal-ion upwellings at 800-km altitude: an ionospheric signature of the cleft ion fountain. J. Geophys. Res. 94, 15277-15290 (1989). doi:10.1029/JA094iA11p15277

R.M. Winglee, D. Chua, M. Brittnacher, G.K. Parks, G. Lu, Global impact of ionospheric outflows on the dynamics of the magnetosphere and cross-polar cap potential. J. Geophys. Res. 107, A9 (2002). doi:10.1029/2001JA000214

A.W. Yau, M. Andre, Sources of ion outflow in the high latitude ionosphere. Space Sci. Rev. 80(1-2), 1-26 (1997)

A.W. Yau, E.G. Shelley, W.K. Peterson, L. Lenchyshyn, Energetic auroral and polar ion outflow at DE-1 altitudes: magnitude, composition, magnetic activity dependence and long-term variations. J. Geophys. Res. 90, 8417-8432 (1985)

A.W. Yau, W.K. Peterson, E.G. Shelley, Quantitative parametrization of energetic ionospheric ion outflow, in Modeling Magnetospheric Plasma, ed. by T.E. Moore, J.H. Waite Jr. Geophysical Monograph, vol. 44 (Am. Geophys. Union, Washington, 1988), pp. 211-217

A.W. Yau, H.G. James, W. Liu, The Canadian Enhanced Polar Outflow Probe (e-POP) mission in ILWS. Adv. Space Res. 38(8), 1870-1877 (2006)

A.W. Yau, T. Abe, W.K. Peterson, The polar wind: recent observations. J. Atmos. Sol.-Terr. Phys. 69, 19361983 (2007)

A.W. Yau, T. Abe, W.K. Peterson, Influences of the ionosphere, thermosphere and magnetosphere on ion outflows, in The Dynamic Magnetosphere, ed. by W. Liu, M. Fujimoto. IAGA Special Sopron Book Series, vol. 3 (Springer, Berlin, 2011), pp. 283-314. doi:10.1007/978-94-007-0501-2_16

E. Yizengaw, M.B. Moldwin, P.L. Dyson, B.J. Fraser, S. Morley, First tomographic image of ionospheric outflows. Geophys. Res. Lett. 33, L20102 (2006). doi:10.1029/2006GL027698 